\title{
Perbedaan Nilai Agregasi Trombosit Akibat Pengaruh Penggunaan Analgesia Ketorolak dan Ibuprofen Intravena Pascaoperasi di RSUP Haji Adam Malik Medan
}

\author{
Dewi Yuliana Fithri, Dadik Wahyu Wijaya, Hasanul Arifin \\ Fakultas Kedokteran Universitas Sumatera Utara/ \\ Departemen Anestesiologi dan Terapi Intensif RSUP Haji Adam Malik Medan
}

\begin{abstract}
Abstrak
Obat anti-inflamasi nonsteroid (OAINS) merupakan analgetik yang sering digunakan pada pascaoperasi bedah ortopedi. Penelitian ini bertujuan melihat apakah terdapat perbedaan nilai agregasi trombosit akibat pengaruh penggunaan analgestik ketorolak dengan ibuprofen intravena setelah operasi. Penelitian ini merupakan penelitian uji klinis dengan uji acak tersamar buta ganda yang membandingkan perbedaan pengaruh ketorolak $30 \mathrm{mg}$ intravena/ 6 jam dengan ibuprofen $800 \mathrm{mg}$ intravena/ 6 jam. Populasi penelitian ini adalah pasien yang menjalani tindakan pembedahan elektif dengan anestesi umum di RSUP Haji Adam Malik Medan pada bulan Agustus 2016. Pasien dibagi menjadi 2 kelompok dengan tiap-tiap kelompok berjumlah 20 pasien. Ketorolak atau ibuprofen sebagai analgetik diberikan setelah 30 menit selesai operasi, kemudian dilanjutkan per 6 jam sampai dengan 2 hari selesai operasi. Uji statistik menggunakan tes Wilcoxon untuk sebelum perlakuan dan Uji Mann-Whitney untuk sesudah perlakuan pada kedua kelompok. Data karakteristik subjek homogen. Agregasi trombosit pada kelompok ketorolak dengan kelompok ibuprofen berbeda bermakna setelah 10 menit ekstubasi dengan 8 jam setelah pemberian obat terakhir. Tidak terdapat perbedaan bermakna antara kelompok ketorolak dan kelompok ibuprofen setelah 10 menit ekstubasi $(p>0,05)$, namun terdapat perbedaan bermakna pada 8 jam setelah akhir pemberian obat. Simpulan, ketorolak menurunkan persentase agregasi trombosit lebih besar daripada ibuprofen setelah 8 jam pemberian obat terakhir.
\end{abstract}

Kata kunci: Agregasi trombosit, analgetik pascaoperasi, ibuprofen, ketorolak

\section{Differences in Platelet Aggregation Values in Postoperative Intravenous Ketorolac and Ibuprofen Analgesics at Haji Adam Malik Central General Hospital Medan}

\begin{abstract}
Non-steroidal anti-inflammatory drugs (NSAIDs) are analgesics used for postoperative orthopedic surgery. This study aimed to underrstand the effect of intravenous ketorolac and ibuprofen on platelet aggregation values. This was a double-blind randomized controlled trial that compared the effects of intravenous ketorolac and ibuprofen. The population of this study were patients undergoing elective surgery under general anesthesia at Haji Adam Malik Central General Hospital Medan in August 2016. Patients were divided into 2 groups (n: 20): ketorolac group andibuprofen group. Both group received analgesic 30 minutes after surgery up to 2 days postoperative. The statistical tests used were Wilcoxon test for pre-treatment and Mann-Whitney test for post-treatment in each group. Subject characteristic data were homogenous. Platelet aggregation of ketorolac and ibuprofen groups differed significantly between 10 minutes after extubation and 8 hours after the last drug administration. There was no significant difference between the ketorolac and ibuprofen groups after 10 minutes of extubation ( $p>0.05$ ); however there was a significant difference at 8 hours after the end of drug administration. In conclusion, ketorolac decreases platelet aggregation percentage greater than ibuprofen after 8 hours of the last drug administration.
\end{abstract}

Key words: Ibuprofen, ketorolac, platelet aggregation, postoperative analgesia

Korespondensi: Dewi Yuliana Fithri, dr., SpAn, Departemen Anestesiologi dan Terapi Intensif Fakultas Kedokteran Universitas Sumatera Utara/RSUP Haji Adam Malik Medan, Jl. Bunga Lau No 17, Kemenangan Tani, Medan Tuntungan, Kota Medan, Sumatera Utara 20136, Email dewiyulianafithri@gmail.com 


\section{Pendahuluan}

Nyeri merupakan pengalaman yang tidak menyenangkan bagi pasien pascabedah. Cedera jaringan atau proses inflamasi akut memicu pengeluaran berbagai mediator inflamasi seperti katekolamin, bradikinin, prostaglandin, histamin, 5-hidroksitriptamin, leukotrien, amin, purin, dan sitokin yang dapat mengaktivasi atau mensensitisasi nosiseptor secara langsung ataupun tidak langsung. Pengelolaan nyeri pascabedah yang optimal dapat menurunkan morbiditas pasien. Angka morbiditas pascabedah yang tinggi akan berakibat bertambahnya waktu penyembuhan dan lama tinggal, serta bertambahnya biaya rawat di rumah sakit. Pengelolaan nyeri pascabedah yang optimal bukan hanya sebagai upaya mengurangi penderitaan, tetapi juga untuk meningkatkan kualitas hidup pasien. Tanpa pengelolaan nyeri pascabedah yang adekuat, pasien akan mengalami gangguan fisiologis maupun psikologis yang dapat meningkatkan angka morbiditas dan mortalitas secara bermakna. ${ }^{1,2}$

Tujuan pengelolaan nyeri pada pascabedah adalah untuk kenyamanan pasien dan juga menghambat alur respons stres akibat pembedahan. Pengelolaan nyeri pascabedah yang ideal harus pain-free dan stress-free. Pengelolaan nyeri pascabedah yang efektif membuat pasien leluasa melakukan gerak napas, batuk, dan mobilisasi sehingga penyembuhan berlangsung lebih cepat. ${ }^{3}$

Beberapa penelitian menyatakan bahwa ketorolak merupakan analgesik golongan obat anti-inflamasi non-steroid (OAINS) yang sering digunakan pascaoperasi yang memiliki efek samping memperpanjang waktu perdarahan dan menghambat agregasi trombosit..$^{3-5}$

Ketorolak menghambat agregasi trombosit dan dapat memperpanjang waktu perdarahan. Efek terhadap penghambatan agregasi akan hilang dalam waktu 24 jam sampai 48 jam setelah obat itu dihentikan. Penghambatan agregasi trombosit ini berlangsung melalui proses penghambatan sintesis tromboksan A2. ${ }^{5-7}$

Penelitian yang telah membandingkan efek ketoprofen, ketorolak, dan diklofenak terhadap trombosit menunjukkan ketorolak, ketoprofen, dan juga diklofenak menyebabkan disfungsi trombosit, namun diklofenak mempunyai efek yang singkat dibanding dengan ketorolak yang bertahan lebih dari 24 jam. $^{8}$

Penelitian tentang fungsi trombosit setelah penggunaan ketorolak secara intravena dan parasetamol secara intravena menunjukkan bahwa parasetamol menyebabkan disfungsi trombosit yang bersifat reversibel serta menurunkan agregasi trombosit dan kadar maksimal $\mathrm{TxB}_{2}$, sedangkan pada ketorolak terjadi inhibisi agregasi trombosit, bentuk formasi $\mathrm{TxB}_{2}$, dan fungsi trombosit yang tetap bertahan selama 24 jam. $^{9}$

Penelitian terhadap 11 relawan yang mendapatkan ibuprofen $600 \mathrm{mg} / 8$ jam selama 7 hari menunjukkan penurunan agregrasi trombosit, namun kembali normal dalam waktu 24 jam setelah pemberian ibuprofen dihentikan. ${ }^{10}$

Penelitian yang lain menyatakan bahwa ibuprofen tidak menyebabkan pemanjangan waktu perdarahan dan peningkatan risiko perdarahan meskipun kelompok ibuprofen telah menerima heparin dosis rendah. ${ }^{11}$

Ibuprofen dapat mencegah penghambatan agregasi trombosit yang ireversibel yang dihasilkan oleh aspirin untuk profilaksis strok sekunder dan interaksi ini dapat terjadi pada pasien yang menggunakan obat aspirin. ${ }^{12,14}$

Ketorolak intravena adalah OAINS yang sering dipergunakan untuk mengatasi nyeri pascabedah karena obat mudah didapat dan relatif murah. ${ }^{13}$ Namun, ibuprofen intravena adalah sediaan baru di Indonesia yang sedang dikembangkan penggunaannya.

Penelitian ini bertujuan melihat perbedaan nilai agregasi trombosit akibat pengaruh penggunaan antara analgetik ketorolak dan ibuprofen intravena setelah operasi

\section{Subjek dan Metode}

Penelitian ini merupakan uji klinis secara acak tersamar buta ganda yang membandingkan perbedaan pengaruh ketorolak dengan ibuprofen intravena sebagai analgesia 
pascaoperasi terhadap agregrasi trombosit. Populasi penelitian ini adalah pasien yang menjalani tindakan pembedahan elektif dengan anestesi umum di RSUP Haji Adam Malik Medan pada bulan Agustus 2016. Sampel penelitian adalah populasi yang telah memenuhi kriteria inklusi dan tidak termasuk eksklusi.

Kriteria inklusi adalah operasi ortopedi elektif usia 19-60 tahun, status fisik menurut American Society of Anesthesiologist (ASA) kelas I dan II. Kriteria eksklusi adalah pasien dengan riwayat alergi terhadap OAINS, mengonsumsi obat antikoagulan, kadar trombosit $<100.000 / \mu \mathrm{L}$, perdarahan kelas IIIII, mendapatkan pemberian koloid $>1.000$ $\mathrm{mL}$, mendapatkan transfusi darah, riwayat diabetes melitus, merokok, hipertensi, hamil, dan menyusui.

Kriteria putus uji pada penelitian ini: pasien mengalami alergi, syok anafilaktik, dan mendapatkan antikoagulan pascaoperasi. Untuk menentukan besar sampel dilakukan perhitungan yang sesuai dengan penelitian serta mempertimbangkan angka putus uji dan didapatkan jumlah sampel adalah 40 orang. Pasien ASA I dan II yang dijadwalkan untuk dilakukan operasi dengan anestesi umum saat tiba di kamar operasi dilakukan identifikasi jenis kelamin, usia, berat badan, status fisik (ASA), dan monitoring vital sign. Dilakukan randomisasi dengan cara randomisasi blok oleh relawan yang telah dilatih, selanjutnya disebut relawan pertama.

Kelompok perlakuan dibagi menjadi dua kelompok, yaitu kelompok ketorolak dan kelompok ibuprofen. Jumlah kombinasi sekuens adalah 2. Dengan mata tertutup, pena dijatuhkan di atas tabel random. Ambil angka dua digit, angka yang ditunjuk oleh pena tadi merupakan nomor awal untuk menentukan sekuens. Kemudian, pilihlah angka ke bawah dari angka pertama tadi sampai diperoleh jumlah sekuens yang sesuai dengan besarnya sampel. Dilakukan premedikasi dengan midazolam 0,1 $\mathrm{mg} / \mathrm{kgBB}$ intravena dan fentanil $2 \mu \mathrm{g} / \mathrm{kgBB}$ dan induksi dilakukan dengan propofol $2 \mathrm{mg} / \mathrm{kgBB}$ intravena oleh relawan sampai refleks bulu mata hilang. Kemudian, diberikan atrakurium $0,5 \mathrm{mg} / \mathrm{kgBB}$

Tabel 1 Karakteristik Subjek

\begin{tabular}{lccc}
\hline & $\begin{array}{c}\text { Kelompok Ketorolak } \\
\mathbf{n = 2 0}\end{array}$ & $\begin{array}{c}\text { Kelompok Ibuprofen } \\
\mathbf{n = 2 0}\end{array}$ & $\mathbf{p}$ \\
\hline Jenis kelamin (n) & & 12 & $0,337^{\mathrm{a}}$ \\
Laki-laki & 10 & 8 & \\
Perempuan & 10 & $43,2(16,4)$ & $0,766^{\mathrm{b}}$ \\
Usia, rata-rata (SD) tahun & $42,5(14,3)$ & $58,9(5,6)$ & $0,663^{\mathrm{b}}$ \\
Berat badan, rata-rata (SD) kg & $58,3(4,9)$ & 9 & $0,342^{\mathrm{a}}$ \\
ASA & 12 & 11 & \\
I & 8 & & \\
II & & & \\
\hline
\end{tabular}

Keterangan: ${ }^{\mathrm{a} C h i}$ square, ${ }^{\mathrm{b}}$ Mann-Whitney

Tabel 2 Perbedaan Agregasi Trombosit Kelompok Ketorolak pada 10 Menit Setelah Ekstubasi dengan 8 Jam Setelah Pemberian Obat Terakhir

\begin{tabular}{lccc}
\hline \multirow{2}{*}{ Agregasi Trombosit } & Median (IQR) & Z & Uji Statistik \\
\cline { 3 - 4 } & & & \\
\hline $\mathrm{T}_{0}$ & $47,8(42,7-61)$ & 3,928 & 0,001 \\
$\mathrm{~T}_{1}$ & $43,0(40,1-57,4)$ & & \\
\hline
\end{tabular}

Keterangan: uji Wilcoxon 
Tabel 3 Perbedaan Agregasi Trombosit Kelompok Ibuprofen pada 10 Menit Setelah Ekstubasi dengan 8 Jam Setelah Pemberian Obat Terakhir

\begin{tabular}{lccc}
\hline \multirow{2}{*}{ Agregasi Trombosit } & Median (IQR) & \multicolumn{2}{c}{ Uji Statistik } \\
\cline { 3 - 4 } & & $\mathbf{Z}$ & $\mathbf{p}$ \\
\hline $\mathrm{T}_{0}$ & $46,6(40,1-55,2)$ & 3,922 & 0,001 \\
$\mathrm{~T}_{1}$ & $45,9(39,2-54,4)$ & & \\
\hline
\end{tabular}

Keterangan: uji Wilcoxon

dan dilakukan intubasi endotrakeal. Rumatan menggunakan sevofluran 1-2 vol\%, $\mathrm{O}_{2}: \mathrm{N}_{2} \mathrm{O}=$ 50\%:50\%. Sepuluh menit setelah ekstubasi, dilakukan pengambilan sampel darah pertama pada kedua kelompok dan dimasukkan ke dalam vacuum container. Setelah 30 menit selesai operasi, diberikan ketorolak $30 \mathrm{mg} /$ IV/6 jam pada kelompok keterolak dan ibuprofen $800 \mathrm{mg} / \mathrm{IV} / 6$ jam pada kelompok ibuprofen selama 2 hari. Pemberian ketorolak dan ibuprofen dilakukan dengan melarutkan dalam $100 \mathrm{~mL} \mathrm{NaCl}$ 0,9\% dan didrips selama 30 menit. Pengambilan sampel darah kedua dilakukan pada 8 jam pascapemberian analgetik terakhir. Sampel darah diperiksa nilai agregasi trombosit dengan agregometer dari chrono-log dan PACK-4 Helena menggunakan ADP 1, 2, dan $10 \mu \mathrm{mol}$ (ADP eksogen).

\section{Hasil}

Penelitian ini diikuti oleh 40 orang yang memenuhi kriteria inklusi dan tidak termasuk eksklusi yang dibagi menjadi 2 kelompok, yaitu kelompok A yang mendapatkan ketorolak dan kelompok B yang mendapatkan ibuprofen sebagai analgetik pascaoperasi.

Jumlah karakteristik subjek (Tabel 1) laki-laki sama dengan perempuan masingmasing 10 orang. Pada kelompok ibuprofen terdiri atas laki-laki 12 orang dan perempuan 8 orang. Usia rata-rata kelompok ketorolak 42,5 tahun dengan standar deviasi 14,3 dan pada kelompok ibuprofen 43,2 tahun dengan standar deviasi 16,4. Berat badan rata-rata kelompok ketorolak 58,3 kg dengan standar deviasi 4,9 dan kelompok ibuprofen 58,9 kg dengan standar deviasi 5,6. Kelompok ketorolak terdiri atas 12 orang ASA I dan 8 orang ASA II. Kelompok ibuprofen terdiri atas 9 orang ASA I dan 11 orang ASA II sehingga dapat disimpulkan subjek homogen.

Hasil analisis menggunakan uji Wilcoxon menunjukkan perbedaan agregasi trombosit signifikan antara kedua pengamatan pada kelompok ketorolak $(\mathrm{p}<0,05)$ yang terjadi penurunan agregasi trombosit setelah 8 jam pemberian obat terakhir.

Hasil analisis menggunakan uji Wilcoxon menunjukkan perbedaan agregasi trombosit yang signifikan antara kedua pengamatan pada kelompok ibuprofen $(\mathrm{p}<0,05)$, terjadi penurunan agregasi trombosit setelah 8 jam pemberian obat terakhir.

Analisis lanjutan dengan uji Mann-Whitney (Tabel 4) tidak terdapat perbedaan agregasi antara trombosit kelompok ketorolak dan kelompok ibuprofen saat 10 menit setelah ekstubasi $(p>0,05)$. Terdapat perbedaan agregasi trombosit pada kelompok ketorolak

Tabel 4 Perbedaan Agregasi Trombosit antara Kelompok Ketorolak dan Kelompok Ibuprofen

\begin{tabular}{lcccc}
\hline Agregasi Trombosit & $\begin{array}{c}\text { Ketorolak } \\
\text { Mean Rank }\end{array}$ & $\begin{array}{c}\text { Ibuprofen } \\
\text { Mean Rank }\end{array}$ & U & p \\
\hline $\mathrm{T}_{0}$ & 22,95 & 18,05 & 151 & 0,185 \\
$\mathrm{~T}_{1}$ & 20,66 & 19,48 & 179 & 0,001 \\
\hline
\end{tabular}

Keterangan: uji Mann-Whitney 
dengan ibuprofen pada 8 jam setelah pemberin obat terakhir $(\mathrm{p}<0,05)$.

\section{Pembahasan}

Karakteritik subjek berdasarkan jenis kelamin, usia, dan berat badan homogen pada kedua kelompok penelitian sehingga layak untuk dibandingkan.

Nilai median dan IQR (interquartile range) pada 10 menit setelah ekstubasi dengan setelah 8 jam pemberian ketorolak terakhir mengalami penurunan yang bermakna. Hal ini menunjukkan pemberian ketorolak selama 48 jam memengaruhi agregasi trombosit. Pada tahun 2009 dilakukan penelitian yang hasilnya terdapat penurunan agregasi trombosit pada keterolak menit ke- 45 dan 2 hari setelah pemberian obat. Pada tahun 2009 juga dilakukan penelitian yang menunjukkan ketorolak trometamin menghambat signifikan agregasi trombosit dengan menginhibisi siklo-oksigenase dan menurunkan produksi tromboksan A1. Selain itu, juga menginhibisi agregasi trombosit dalam respons terhadap kolagen dan asam arakidonat.

Agregasi trombosit menurun 25\% setelah pemberian ketorolak. Agregasi trombosit akan terhambat dan disfungsi trombosit ini akan terus terlihat setelah 24 jam pemberian keterolak. Efek terhadap penghambatan agregasi akan hilang dalam waktu 24 jam sampai 48 jam setelah obat dihentikan. . $^{10,15}$

Perbandingan nilai median dan IQR pada menit ke-10 setelah ekstubasi dengan setelah 8 jam pemberian ibuprofen terakhir akan mengalami penurunan yang bermakna. Hal ini menunjukkan pengaruh pemberian ibuprofen selama 48 jam terhadap agregasi trombosit. Hasil penelitian pada tahun 2015 menunjukkan ibuprofen menginhibisi agregasi trombosit pada dosis yang direkomendasikan, tetapi tidak mengganggu aPTT ataupun profil koagulasi. Efek ibuprofen itu bersifat lemah, namun dapat kembali normal dalam waktu 24 jam. Hal ini juga sesuai dengan sebuah penilitian pada tahun 2016 terdapat efek penghambatan trombosit bergantung pada dosis yang diberikan karena ibuprofen dapat menghambat agregasi trombosit dan menghambat konversi asam $14 \mathrm{C}$-arakidonat menjadi tromboksan $\mathrm{A}_{2}{ }^{12,16}$

Uji beda Mann-Whitney pada kelompok ketorolak dengan kelompok ibuprofen tidak ditemukan perbedaan bermakna agregasi trombosit setelah dilakukan ekstubasi, namun terdapat perbedaan bermakna 8 jam setelah pemberian obat terakhir.

Faktor perbandingan COX-1 dan COX2 sangat berhubungan dengan perdarahan karena semakin besar nilai COX-1 maka risiko tinggi perdarahan. Secara farmakologi bila ketorolak dibanding dengan ibuprofen didapatkan ketorolak menghambat COX secara nonselektif dan perbandingan COX-1:COX-2 adalah 330:1 sehingga risiko lebih tinggi terjadi perdarahan dan gangguan gastrointestinal. Ibuprofen bekerja dengan cara menghambat enzim COX-1 dan COX-2 dalam mengonversi asam arakidonat menjadi prostaglandin. Ibuprofen menghambat aktivitas enzim COX1 dan COX-2 dengan perbandingan 2,5:1 sehingga risiko perdarahan atau gangguan gastrointestinal dan ginjal lebih rendah.

\section{Simpulan}

Berdasar atas penelitian ini, dapat disimpulkan penurunan agregasi trombosit pada pemakaian ketorolak 48 jam setelah operasi lebih besar daripada ibuprofen. Ketorolak menurunkan persentase agregasi maksimal trombosit lebih besar daripada ibuprofen setelah 8 jam pemberian obat terakhir.

\section{Daftar Pustaka}

1. Shrestha A, Huang D. Intravenous ibuprofen as an adjunct in acute postoperative pain. JSAN. 2015;2(1):21-4.

2. Ahiskalioglu EO, Ahiskalioglu A, Aydin P, Yayik AM, Temiz A. Effects of singledose preemptive intravenous ibuprofen on postoperative opioid consumption and acute pain after laparoscopic cholecystectomy. Medicine (Baltimore). 2017;96(8):e6200-1.

3. Beckman JA, Creager MA, Libby P. Diabetes 
and atherosclerosis: epidemiology, pathophysiology, and management. JAMA. 2008;287(19):2570-81.

4. Dame L, Bisri T, Wargahadibrata $\mathrm{H}$. Perbandingan deksketoprofen trometamol $1,5 \mathrm{mg} / \mathrm{kgBB}$ dan petidin $1 \mathrm{mg} / \mathrm{kgBB}$ intravena sebagai analgetik intraoperasi dan kejadian efek samping pascaoperasi pada pasien bedah rawat jalan RSUP Dr. Sadikin Bandung. Anesth Crit Care. 2007;2007(25):217-20.

5. Hintzen C. Double-blinded randomized trial of IV ibuprofen and morphine combination therapy in patients presenting to the emergency department with renal colic. [PhD dissertation]. Arizona: The University of Arizona; 2015.

6. Rahman K, Lowe G, Smith S. Aged garlic extract inhibits human platelet aggregation by altering intracellular signaling and platelet shape change. J Nutr. 2016;146(2):410S-5.

7. Stoelting RK, Miller RD, penyunting. Fluid and blood therapy: basics of anaesthesia. Edisi ke-4. Philadelphia: Churchill Livingstone; 2016.

8. Singla L, Rock A, Pavliv L. A multi-center, randomized, double-blind placebocontrolled trial of intravenous-ibuprofen (IV-ibuprofen) for treatment of pain in post-operative orthopaedic adult patients. Pain Med. 2010;11(8):1284-93.

9. Hong Y, Gengo FM, Rainka MM, Bates VE, Mager DE. Population pharmacodynamic modelling of aspirin- and ibuprofeninduced inhibition of platelet aggregation in healthy subjects. Clin Pharmacokinet. 2008;47(2):129-37.

10. Burke A, Smyth E, Fitzgerald GA, penyunting. Analgesic-antipyretic agents:
Goodman \& Gilman's the pharmacological basis of therapeutics. Edisi ke-11. New York: The McGraw- Hill Companies; 2009.

11. Southworth S, Peters J, Rock A, Pavliv L. A multicenter, randomized, double-blind, placebo-controlled trial of intravenous ibuprofen 400 and $800 \mathrm{mg}$ every 6 hours in the management of postoperative pain. Clin Therapeut. 2009;31(9):1922-35.

12. Gupta A, Abubaker H, Demas E. A randomized trial comparing the safety and efficacy of intravenous ibuprofen versus ibuprofen and acetaminophen in knee or hip arthroplasty. Pain Physic. 2016;19(1):349-56.

13. Silva BR, Pernomian L, De Paula TD, Grando MD, Bendhack LM. Endothelial nitric oxide synthase and cyclooxygenase are activated by hydrogen peroxide in renal hypertensive rat aorta. Eur J Pharmacol. 2017;813(1):1-5.

14. Fries D, Innerhofer P, Klinger A, Berresheim U, Mittermayr M, Calatzis A, dkk. The effect of the combined administration of colloids and lactated ringer's solution on the coagulation system: an in vitro study using thrombelastograph $\AA$ coagulation analysis (ROTEG®). Anesth Analg. 2009;94(5):1280-7.

15. Ratri S, Perbedaan pengaruh pemberian ketorolak dan deksketoprofen sebagai analgesia pasca bedah terhadap agregasi trombosit. Eprints.undip.ac.id. 2009

16. Martini. Original research article a multicenter, randomized, double-blind placebocontrolled trial of intravenous-ibuprofen (IV-ibuprofen) for treatment of pain in post-operative orthopedic adult patients. Pain Med. 2015;11:1284-93. 